\title{
Use of Fenestrated Tracheostomy Tubes: A Comparative Study
}

\author{
Somu Lakshmanan ${ }^{1}$, Shiva Priya Jeyabalakrishnan ${ }^{2}$, Prasanna K Saravanam ${ }^{3}$
}

\begin{abstract}
Introduction: Tracheostomy is commonly performed in patients requiring long-term ventilator support. There are many types of tracheostomy tubes like fenestrated and non-fenestrated tubes. This study is to compare the types of fenestrated tubes. Type I is a fenestrated tube with multiple small fenestrae and type II is a fenestrated tracheostomy tube with a single large fenestra.

Materials and methods: A total of 87 patients who underwent tracheostomy due to prolonged ventilation from January 2015 to January 2016 were included in the study. Type I tube was used in 40 patients and type II tube was used in 47 patients. Tube change was done on the 10 th day, at the end of 1 month, and at the end of 3 months. Flexible laryngoscopy is done during every tube change to assess the airway.

Results: Two groups were compared in terms of granulation through fenestra, stomal granulation, frequency of suctioning, and inner tube block. Statistical analysis was done and the values were compared. A $p$ value $<0.05$ was considered to be statistically significant. There was a statistically significant difference between both groups in terms of less incidence of granulation through the fenestra and stomal granulation in type II tube. Conclusion: Type II tubes are more patient compliant. The incidence of inner tube block is comparatively less which makes it safe to use and avoid life-threatening situations. Decannulation can be done earlier and without complications in patients with type II tubes due to the less incidence of stomal granulation. Thus, type II tube is safer to use and has minimal complications.

Keywords: Fenestrated, Fol, Granulation, Stomal granulation, Tracheostomy tubes.

International Journal of Head and Neck Surgery (2021): 10.5005/jp-journals-10001-1419
\end{abstract}

\section{INTRODUCTION}

Tracheostomy is one of the most commonly conducted procedures in critically ill patients requiring long-term ventilator support. ${ }^{1}$ Regular tracheostomy tube change has to be done to prevent the occurrence of granulation and its complications. ${ }^{2}$ For the selection of tracheostomy tubes, both the Intensive Care Society UK (ICS) guidelines and manufacturers issued advice regarding the use of fenestrated tracheostomy tubes in the early stage of stoma formation. ${ }^{3}$ Cuffed tracheostomy tubes were used for all patients. ${ }^{4}$

Studies have been conducted about the various complications and incidence of granulation formation in fenestrated tracheostomy tubes. But there is no consensus in the literature describing the of fenestra in tracheostomy tubes (single or multiple fenestrae) $)^{5}$ and their comparison in terms of granulation formation.

The objective of this study is to compare the advantages and disadvantages in terms of granulation adjacent to the fenestra, stomal granulation, frequency of suctioning, and incidence of inner tube blocks in two types of fenestrated tracheostomy tubes.

Type I tube has multiple small fenestrae in the outer cannula and type II tube has a single large fenestra in the outer cannula.

\section{Materials and Methods}

One hundred and seventeen patients underwent surgical tracheostomy for prolonged ventilation in our tertiary care hospital between January 2015 and January 2016. Patients with indications other than prolonged ventilation were excluded from the study. They were followed up till they were successfully decannulated for a period of 6 months. Nineteen of these patients died from causes unrelated to the tracheostomy. Eleven patients were lost to follow-up. A total of 87 patients were included in the study. There were 52 males and 35 females with a mean age of 46 years (ranging from 1 to 87 years).

\footnotetext{
1,2Department of Otorhinolaryngology, Sri Ramachandra Medical College and Research Institute, Chennai, Tamil Nadu, India

${ }^{3}$ Department of ENT, Head and Neck Surgery, Sri Ramachandra Medical College and Research Institute, Chennai, Tamil Nadu, India
}

Corresponding Author: Shiva Priya Jeyabalakrishnan, Department of Otorhinolaryngology, Sri Ramachandra Medical College and Research Institute, Chennai, Tamil Nadu, India, e-mail: shivapriya2020@gmail. com

How to cite this article: Lakshmanan S, Jeyabalakrishnan SP, Saravanam PK. Use of Fenestrated Tracheostomy Tubes: A Comparative Study. Int J Head Neck Surg 2021;12(1):15-18.

Source of support: Nil

Conflict of interest: None

A horizontal skin crease incision was applied $2 \mathrm{~cm}$ above the suprasternal notch and dissection was done. The thyroid isthmus was retracted superiorly to reveal the second and third tracheal rings and the tracheal incision was placed between these two rings. A double-lumen cuffed fenestrated (outer fenestrated tube with the non-fenestrated inner cannula) tracheostomy tube was used during the tracheostomy and secured with stay sutures and ties after confirming the position of the tube. The stay sutures were removed on the 5th day and the skin sutures were removed on the 7th day.

On the 10th postoperative day, the tracheostomy tube was changed to either type I (multiple small fenestrae in outer cannula) (Fig. 1) or type II (single large fenestra) (Fig. 2) double-lumen tracheostomy tube. The patients were divided into two groups based on whether a type I (group I) or type II (group II) tracheostomy tube was used.

During every tube change, i.e., on the 10th day, 1 month, 3 months, and before decannulation, a flexible laryngoscopy was 


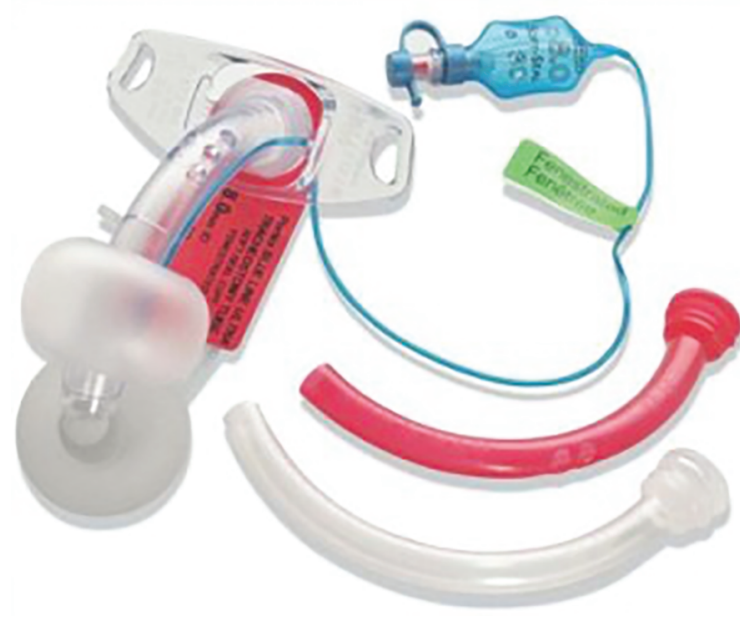

Fig. 1: Tracheostomy tube type I

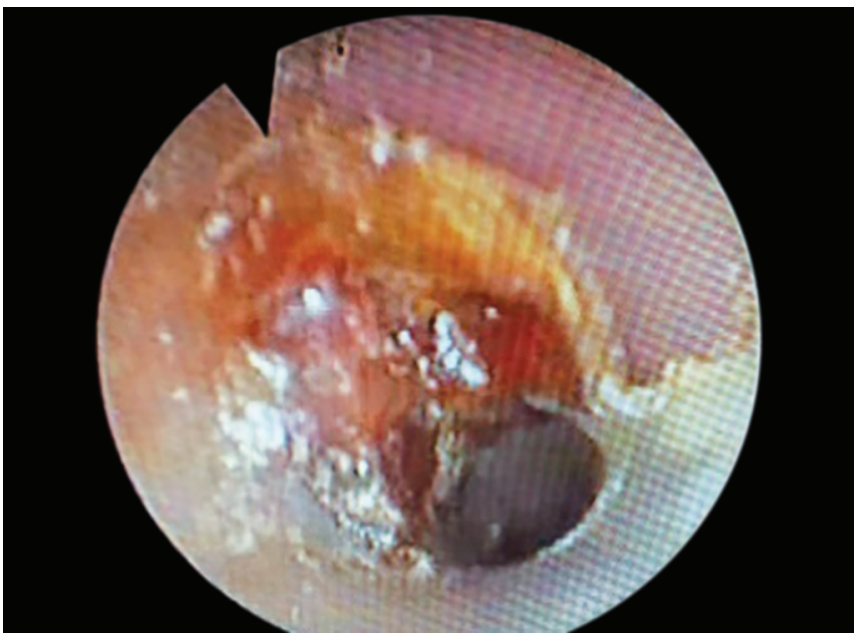

Fig. 3: Granulation through fenestra

done to assess the airway. The patency of the airway, the presence of stomal granulation, and the presence of granulation adjacent to the fenestra were assessed. The above parameters were documented and compared between the two groups.

\section{Statistical Analysis}

The collected data were inserted into Excel spreadsheets and analyzed and evaluated using the Statistical Package of Social Sciences (SPSS) software. Statistical analysis was done to compare both the groups. A $p$ value $<0.05$ was considered to be statistically significant.

\section{Results}

Eighty-seven patients were subjected to a fiber-optic laryngoscopy at the time of tube change, i.e., 10th day, 1 month, 3 months, and at the time of decannulation.

The parameters that were assessed include

- Presence of granulation through the fenestra or adjacent to the fenestra (Fig. 3).

- Presence of stomal granulation (peristomal/suprastomal/ infrastomal).

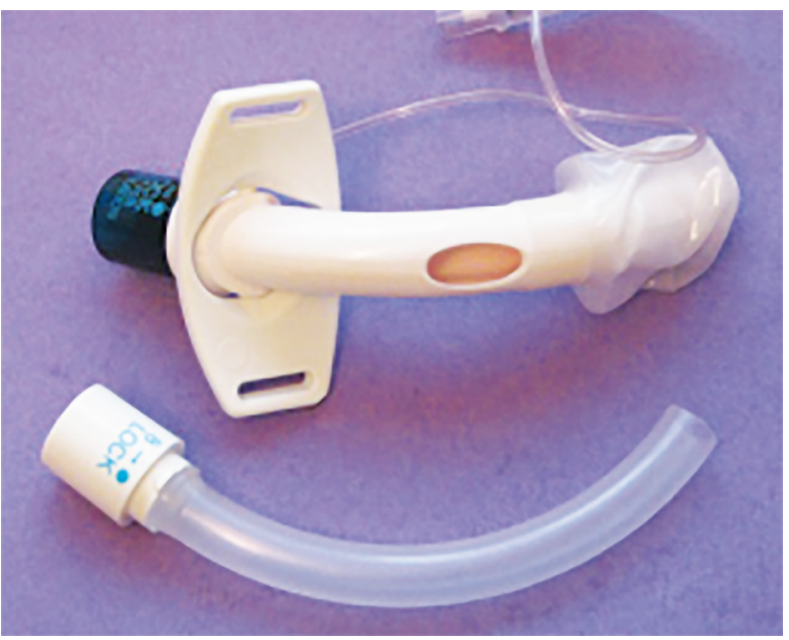

Fig. 2: Tracheostomy tube type II

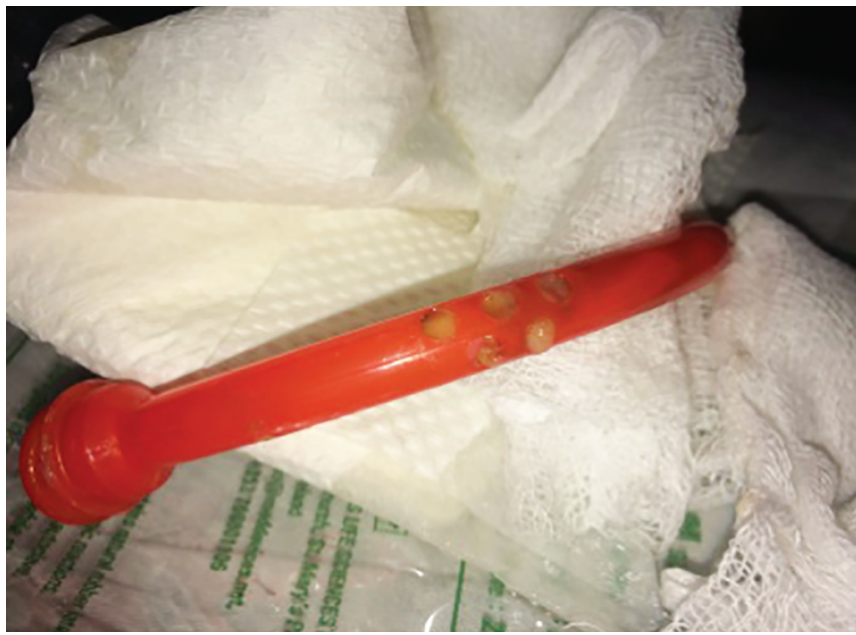

Fig. 4: Tube blocked

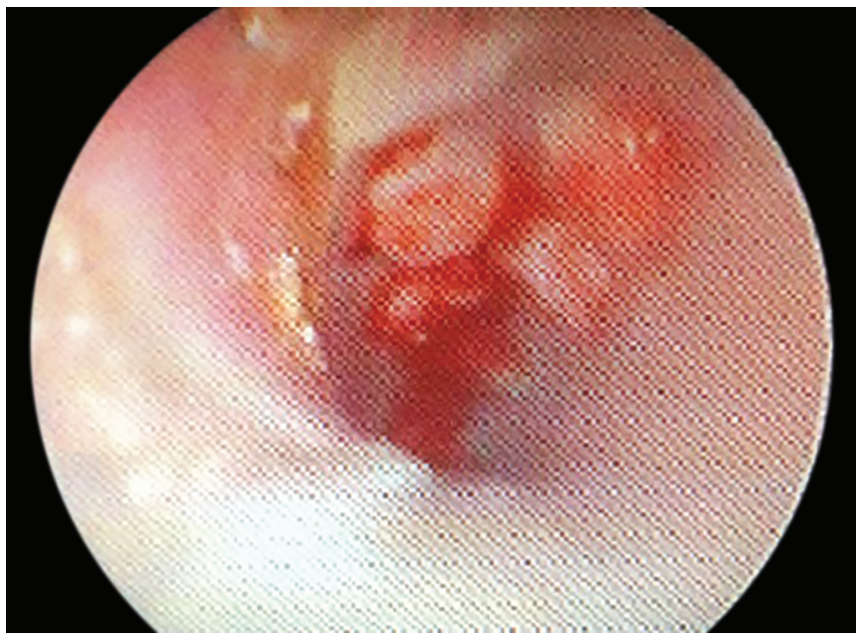

Fig. 5: Inner tube block: the fenestra

- Frequency of daily suctioning.

- Incidence of inner tube block (Figs 4 and 5).

There were a total of 40 patients in group I and 47 patients in group II. 
Table 1: First tube change (10th day)

\begin{tabular}{llll}
\hline & $\begin{array}{l}\text { Type I tube } \\
(n=40)\end{array}$ & $\begin{array}{l}\text { Type II tube } \\
(n=47)\end{array}$ & p value \\
\hline $\begin{array}{l}\text { Granulation through } \\
\text { fenestra }\end{array}$ & 17 & 8 & 0.009 \\
$\begin{array}{l}\text { Stomal granulation } \\
\begin{array}{l}\text { Frequency of suctioning } \\
\text { (per day) }\end{array}\end{array}$ & 12 & 4 & 0.01 \\
Inner tube block & 5 & 3 & 0.325 \\
\hline
\end{tabular}

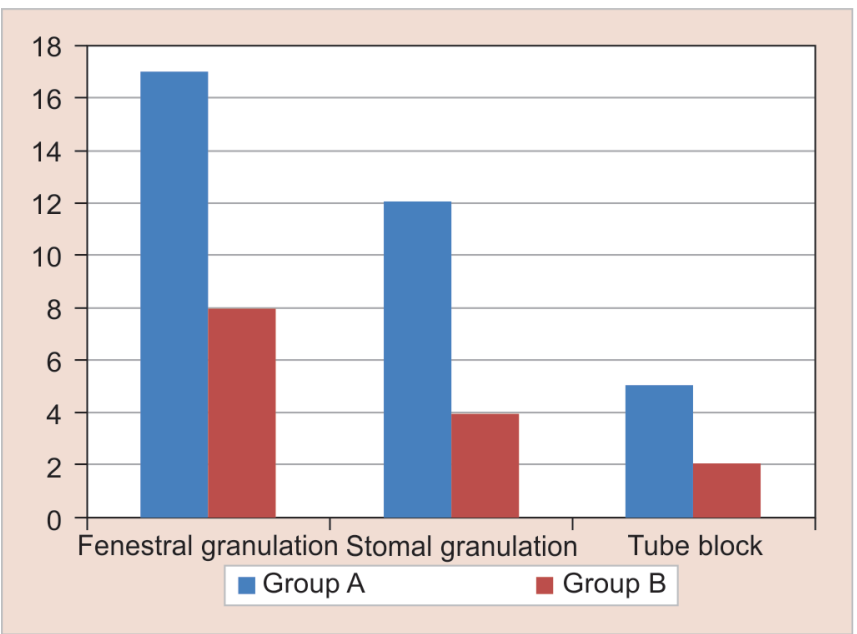

Fig. 6: First tube change

\section{First Tube Change (10th day)}

At the time of the first tube change (10th day), 17 patients in group I and 8 patients in group II had the presence of granulation through the fenestra. Twelve patients in group I and four patients in group Il developed stomal granulation. The frequency of suctioning was average 5 times per day in a group I and 3 times per day in group II. Incidence of inner tube block occurred in five patients in group I and two patients in group II (Table 1 and Fig. 6).

During the first tube change, patients with type II tube showed less incidence of granulation through the fenestra and stomal granulation. A statistically significant difference was seen.

\section{Second Tube Change (End of 1 Month)}

Before the second tube change (at the end of 1 month), 19 patients in group I and 9 patients in group II had the presence of granulation through the fenestra. Eleven patients in group I and six patients in group II developed stomal granulation. The frequency of suctioning was average 5 times per day in a group I and 3 times per day in group II. Incidence of inner tube block occurred in 19 patients in group I and 9 patients in group B (Table 2 and Fig. 7)

A statistically significant difference is obtained between the two groups in terms of comparing granulation through the fenestra and the incidence of inner tube block. Type II tubes were found to have less incidence of granulation through the fenestra and less incidence of inner tube block.

\section{Third Tube Change (End of 3 Months)}

At the end of 3 months, 13 patients in group I and 19 patients in group II were successfully decannulated. Of the rest of the
Table 2: Second tube change (end of 1 month)

\begin{tabular}{llll}
\hline & $\begin{array}{l}\text { Type I tube } \\
(n=40)\end{array}$ & $\begin{array}{l}\text { Type II tube } \\
(n=47)\end{array}$ & $p$ value \\
\hline $\begin{array}{l}\text { Granulation through } \\
\text { fenestra }\end{array}$ & 19 & 9 & 0.005 \\
$\begin{array}{l}\text { Stomal granulation } \\
\begin{array}{l}\text { Frequency of suctioning } \\
\text { (per day) }\end{array}\end{array}$ & 11 & 6 & 0.084 \\
Inner tube block & 5 & 3 & 0.325 \\
\hline
\end{tabular}

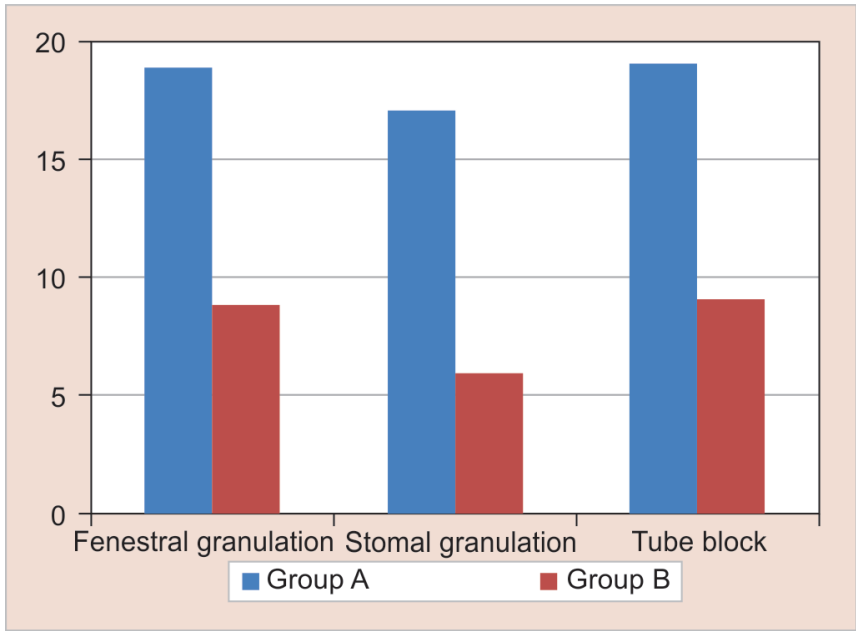

Fig. 7: Second tube change

Table 3: Third tube change (end of 3 months)

\begin{tabular}{llll}
\hline & $\begin{array}{l}\text { Type I tube } \\
(n=27)\end{array}$ & $\begin{array}{l}\text { Type II tube } \\
(n=28)\end{array}$ & p value \\
\hline $\begin{array}{l}\text { Granulation through } \\
\text { fenestra }\end{array}$ & 12 & 6 & 0.069 \\
$\begin{array}{l}\text { Stomal granulation } \\
\begin{array}{l}\text { Frequency of suctioning } \\
\text { (per day) }\end{array}\end{array}$ & 8 & 2 & 0.031 \\
Inner tube block & 5 & 3 & 0.412 \\
\hline
\end{tabular}

patients, 12 patients in group I and 6 patients in group II had the presence of granulation through the fenestra. Eight patients in group I and two patients in group II still had stomal granulation. The frequency of suctioning was average 5 times per day in a group I and 3 times per day in group II. Incidence of inner tube block occurred in four patients in group I and one patient in group II (Table 3).

Type II tube was found to have less incidence of stomal granulation compared to type I tube and a statistically significant difference was obtained.

Two patients in group I required surgical excision of granulation at the time of third tube change.

\section{End of 6 Months}

At the end of 6 months, 38 patients in group I and 44 patients in group II were decannulated. Flexible laryngoscopy done at the time of decannulation showed granulation through the fenestra in seven and two patients in groups I and II, respectively. Evidence of 
stomal granulation was seen in three patients in group I and none of the patients in group II. The frequency of daily suctioning and incidence of inner tube block reduced significantly in both groups.

\section{Discussion}

The comparison between the two types of tubes revealed that the occurrence of granulation through the fenestra and stomal granulation is more common in type I tubes than in type II tube. The presence of granulation through the fenestra and stomal granulation was seen in a greater number of patients in both the groups at the third month. But the number was more in group I than in group II.

With the use of fenestrated tracheostomy tubes despite their many benefits complications like granulation formation adjacent to the fenestrations and also causing obstruction has been reported by Siddharth and Mazzarella. ${ }^{6}$ This is comparable with this study where the occurrence of granulation was seen in both types of tracheostomy tubes.

Bhatia et al. in a case report have suggested that granulation that occludes the fenestra matures, becomes fibrous, and gets covered with epithelium causing narrowing at the level of a stoma. Similar granulation occurred in two patients in this study with partially fenestrated tracheostomy tubes which warranted surgical excision. ${ }^{7}$

Griggs $^{8}$ while explaining the suctioning techniques has stated that suctioning in mechanically ventilated patients should be more than 6 times per day. ${ }^{9,10}$ The frequency of suctioning on an average in this study is 5 times per day and shows no statistical significance between both the groups.

In this study, comparing between both the groups' patients type II fenestrated tracheostomy tubes was found to have statistically less incidence of granulation through fenestra, stomal granulation, and inner tube block (Tables 4 to 6).

Table 4: Statistically significant results: First tube change (10th day)

\begin{tabular}{llll}
\hline & $\begin{array}{l}\text { Type I tube } \\
(n=40)\end{array}$ & $\begin{array}{l}\text { Type II tube } \\
(n=47)\end{array}$ & pvalue \\
\hline $\begin{array}{l}\text { Granulation through } \\
\text { fenestra }\end{array}$ & 17 & 8 & 0.009 \\
$\begin{array}{l}\text { Stomal granulation } \\
\begin{array}{l}\text { Second tube change (end } \\
\text { of 1 month) }\end{array}\end{array}$ & 12 & 4 & 0.01 \\
\hline
\end{tabular}

Table 5: Statistically significant results: Second tube change (end of one month)

\begin{tabular}{llll}
\hline & $\begin{array}{l}\text { Type I tube } \\
(n=40)\end{array}$ & $\begin{array}{l}\text { Type II tube } \\
(n=47)\end{array}$ & p value \\
\hline $\begin{array}{l}\text { Granulation through } \\
\text { fenestra }\end{array}$ & 19 & 9 & 0.005 \\
Inner tube block & 19 & 9 & 0.005 \\
\hline
\end{tabular}

Table 6: Statistically significant results: Third tube change (at the end of three months)

\begin{tabular}{llll}
\hline & $\begin{array}{l}\text { Type I tube } \\
(n=27)\end{array}$ & $\begin{array}{l}\text { Type II tube } \\
(n=28)\end{array}$ & p value \\
\hline Stomal granulation & 8 & 2 & 0.031 \\
\hline
\end{tabular}

The study has its own limitation of having a small sample size. Further research and comparison of various parameters in larger randomized controlled studies may provide clarity about the choice of tube and its appropriate utility.

\section{Conclusion}

Type II fenestrated tracheostomy tubes are more patient compliant. The incidence of inner tube block is comparatively less which makes it safe to use and avoid life-threatening situations. Decannulation can be done earlier and without complications in patients with type II tubes due to the less incidence of stomal granulation. Incidence of granulation through fenestra and bleeding during tracheostomy tube change is less in patients with type II tubes. Thus, type II tube is safer to use and has minimal complications.

\section{Compliance with Ethical Standards}

All of the procedures performed in the present study were done after obtaining ethical clearance from the institution.

\section{References}

1. Cox CE, Carson SS, Holmes GM, et al. Increase in tracheostomy for prolonged mechanical ventilation in North Carolina, 19932002. Crit Care Med 2004;32(11):2219-2226. DOI: 10.1097/01. CCM.0000145232.46143.40.

2. Yaremchuk K. Regular tracheostomy tube changes to prevent formation of granulation tissue. Laryngoscope 2003;113(1):1-10. DOI: 10.1097/00005537-200301000-00001.

3. Plummer AL, Gracey DR. Consensus conference on artificial airways in patients receiving mechanical ventilation. Chest 1989;96(1):178-180. DOI: 10.1378/chest.96.1.178.

4. White AC, Kher S, O'Connor HH. Respiratory care. When to Change a Tracheostomy Tube 2010;55(8):1069-1075.

5. Eisele RF. “Fenestrated tracheostomy tube." U.S. Patent No. 4,852,565. 1 Aug. 1989.

6. Siddharth P, Mazzarella L. Granuloma associated with fenestrated tracheostomy tubes. Am J Surg 150(2):279-280. DOI: 10.1016/00029610(85)90138-2.

7. Bhatia G, Abraham V, Louis L. Tracheal granulation as a cause of unrecognized airway narrowing. J Anaesthesiol, Clin Pharmacol 2012;28(2):235-238. DOI: 10.4103/0970-9185.94907.

8. Griggs A. Tracheostomy: suctioning and humidification. Emerg Nurse 1999;6(9):33-38. DOI: 10.7748/en1999.02.6.9.33.c1259.

9. McGrath BA, Bates L, Atkinson D, et al. Multidisciplinary guidelines for the management of tracheostomy and laryngectomy airway emergencies. Anaesthesia 2012;67(9):1025-1041. DOI: 10.1111/j.13652044.2012.07217.x

10. Ng J, Hamrang-Yousefi S, Agarwal A. Tracheostomy tube change. StatPearls. Treasure Island (FL): StatPearls Publishing; 2020. 